\title{
The effect of digital dermatitis on hoof conformation
}

\author{
A. Gomez, ${ }^{* 1}$ N. B. Cook, ${ }^{*}$ J. Rieman, ${ }^{*}$ K. A. Dunbar, ${ }^{*}$ K. E. Cooley, ${ }^{*}$ M. T. Socha, $†$ and D. Döpfer ${ }^{*}$ \\ *School of Veterinary Medicine, University of Wisconsin, Madison 53706-1102 \\ †Zinpro Corporation, 10400 Viking Dr., Ste. 240, Eden Prairie, MN 55374
}

\section{ABSTRACT}

Digital dermatitis (DD) is the most prevalent cause of lameness of infectious origin in cattle. However, little is known about the effects of DD on hoof conformation (HC) during the clinical disease. The objectives of the present study were to (1) evaluate the changes in $\mathrm{HC}$ observed in feet affected with clinical DD lesions and (2) investigate the temporal relationship between DD and heel horn erosion (HHE). A longitudinal study was carried out including a cohort of 644 Holstein heifers. Digital dermatitis, $\mathrm{HC}$, and presence of $\mathrm{HHE}$ in the rear feet of each heifer were assessed during a period of 6 mo. A total of 1,979 feet evaluations were included in the data set, of which 157 corresponded to feet presenting DD lesions $>20 \mathrm{~mm}$ [mean (SD) size of 27.2 (8.2) $\mathrm{mm}$. Age, days of pregnancy, hip height, and girth circumference were also recorded at cow level. Significant $\mathrm{HC}$ changes were observed in DD-affected feet. Results standardized to a period of $90 \mathrm{~d}$ of follow-up showed an increase in heel height [mean (95\% CI) $3.4(2.5,4.4)$ and $2.8(2.0,3.7) \mathrm{mm}]$ and claw angle $[0.8(0.2,1.4)$ and $1.4(0.7,2.0)$ degrees] of the medial and lateral claws, respectively. In addition, an increase in depth of the interdigital cleft $[3.2(2.7,3.7) \mathrm{mm}]$ and on debris accumulation $[14 \%(7,21)$ of feet] was also observed. Feet affected with clinical DD lesions also experienced a $46 \%$ point increase in the presence of severe HHE. In the short term, $\mathrm{HC}$ changes returned to normal levels when clinical cure of DD was achieved after topical treatment. In conclusion, significant $\mathrm{HC}$ changes occur in heifers affected by clinical DD before lameness symptoms are detected. The transformation of the heel area in feet affected by DD likely promotes the creation of a local environment that favors the persistence of the disease and the occurrence of severe HHE. To avoid further hoof damage, active surveillance and early intervention to reduce $\mathrm{HC}$ changes are recommended to improve DD control programs. Successful restoration of $\mathrm{HC}$ can be achieved upon clinical cure of DD. The long-

Received June 12, 2014.

Accepted October 27, 2014

${ }^{1}$ Corresponding author: gomez3@wisc.edu term effects in lifetime performance of the $\mathrm{HC}$ changes due to DD remain to be further investigated.

Key words: hoof conformation, cattle, digital dermatitis

\section{INTRODUCTION}

Temporal patterns in hoof conformation (HC) changes in dairy cattle have been reported by breed, stage of lactation, or in response to the interaction with different production systems (Becvar et al., 2005; Baird et al., 2009; Bicalho et al., 2009; Telezhenko et al., 2009). Hoof conformation changes have also been associated with the presence of lameness and different claw lesions. Winkler and Margerison (2005) showed a positive association between white line disease and increased length of the dorsal border of the hind feet. Laven (2007) described a significant relationship between digital dermatitis (DD) with both heel height and claw length, and van der Linde et al. (2010) showed significant associations between foot angle variations and different hoof diseases. The pathophysiological mechanisms responsible for the relationship between lameness and $\mathrm{HC}$ can be described at different levels. Examples for these mechanisms are, at the herd level, the adaptation to different walking surfaces such as concrete or rubber, and the adjustment of daily time budgets to varying management characteristics (Telezhenko et al., 2009; Gomez and Cook, 2010; Navarro et al., 2013). At the cow level, positive genetic correlations have been shown between feet and leg traits and hoof lesions (Chapinal et al., 2013; Häggman and Juga, 2013). In addition, changes in gait due to pain and discomfort experienced by animals affected with certain foot pathologies (Flower and Weary, 2009) can affect normal growth and wear. Last, the external (Winkler and Margerison, 2005) and internal (Bicalho et al., 2009) structures of the foot are modified as a reaction to specific claw horn and skin lesions.

Decreased production and well-being associated with lameness and $\mathrm{HC}$ changes are of such importance that a trimming industry has developed with the objective of reestablishing optimal locomotion in cows (Manske et al., 2002) and preserving claw health (Ouweltjes et al., 
Table 1. Demographic characteristics (mean and SD) observed during each evaluation

\begin{tabular}{|c|c|c|c|c|c|c|}
\hline \multirow[b]{2}{*}{ Demographic characteristic } & \multicolumn{2}{|c|}{ Evaluation 1} & \multicolumn{2}{|c|}{ Evaluation 2} & \multicolumn{2}{|c|}{ Evaluation 3} \\
\hline & Mean & $\mathrm{SD}$ & Mean & $\mathrm{SD}$ & Mean & $\mathrm{SD}$ \\
\hline No. of cows & \multicolumn{2}{|c|}{644} & \multicolumn{2}{|c|}{633} & \multicolumn{2}{|c|}{356} \\
\hline Age $(d)$ & 540 & 51 & 635 & 53 & 714 & 47 \\
\hline Girth circumference $(\mathrm{cm})$ & 186 & 8.3 & 194 & 8.1 & 198 & 7.4 \\
\hline Hip height $(\mathrm{cm})$ & 139 & 4.0 & 142 & 3.6 & 144 & 3.6 \\
\hline $\mathrm{DCC}^{1}(\mathrm{~d})$ & 75 & 17.4 & 171 & 21.5 & 250 & 4.3 \\
\hline
\end{tabular}

2009). However, therapeutic trimming interventions are often performed exclusively on animals selected by locomotion scores, overlooking animals with hoof lesions that do not show lameness (Offer et al., 2000; Fjeldaas et al., 2011). Lack of overt lameness when hoof lesions are present is evident for DD and other skin disorders (Frankena et al., 2009). When a case of very severe DD is identified, it is normally associated with lameness and with a marked transformation of the original claw shape. In the field, it is common to find "square" feet, characterized by overgrown heels and shortened claws. However, little is known about potential effects on $\mathrm{HC}$ caused by DD during earlier clinical stages. Laven (2007) and Olechnowicz and Jaskowski (2010) used a cross-sectional design to show a significant association between DD and heel height. Both studies disagreed, however, about changes in dorsal wall length in relation to DD. Additionally, a further knowledge gap exists regarding the temporal relationship between DD and other hoof diseases. For example, the association between heel horn erosion (HHE), a lesion of the heel area generally attributed to lack of hygiene and often observed during the same time periods of high DD risk (Greenough, 2007; Holzhauer et al., 2012), and DD has been shown in studies by Manske et al. (2002) and Capion et al. (2008), but its temporal relationship is unclear.

With the objective of describing how active DD lesions affect $\mathrm{HC}$ and evaluating the temporal relationship between DD and HHE, a longitudinal study was performed in a cohort of pregnant heifers.

The study was approved under the Animal Care and Use Protocol No. V-1525 by the Research Animal Resources Center of the University of Wisconsin-Madison.

\section{MATERIALS AND METHODS}

A cohort of 644 Holstein heifers was recruited on a commercial dairy operation endemically infected with DD. The heifers were housed in a freestall facility, with recycled sand bedding and with headlocks at the feeding bunk. The stocking density was $<1$ cow per stall for the duration of the study, which ran from July 2011 to October 2012. A TMR ration composed of haylage $(65.6 \%)$, wet distillers $(7.3 \%)$, oat hulls $(26.7 \%)$, and a mineral premix $(0.4 \%)$ was delivered once per day. The heifers were eligible to be included in the study if they were pregnant and free of foot skin diseases such as DD, interdigital dermatitis, and HHE upon inspection at enrollment. Baseline demographic characteristics are shown in Table 1.

The rear feet of each heifer were inspected by one of the authors (A. G.) for the presence of DD disease and $\mathrm{HC}$ characteristics at enrollment (evaluation 1), and 2 more times (evaluation 2 and evaluation 3 ) at 3 -mo intervals (interquartile range $=2.7,3.4$ ). Foot evaluations were made in a stand-up chute (M-Series, Comfort Hoof Care, Inc., Baraboo, WI). The dairy was visited 2 to 3 times per week. During each of the evaluations, body measurements, DD diagnosis, and $\mathrm{HC}$ were recorded electronically using a custom made Access database (Microsoft Corp., Redmond, WA).

\section{Demographic Characteristics and Body Measurements}

Age, days of pregnancy (DCC), and health events were obtained from the farm software (DC305, Valley Agricultural Software, Tulare, CA; Table 1). Individual hip height and heart-girth circumference was measured at each evaluation with each heifer standing up in the chute and before any of the legs were attached for inspection. Hip height was measured using a measuring stick (Nasco, Fort Atkinson, WI) placed in between the iliac crests and heart-girth circumference was measured using a tape measure (Weight-By-Breed Dairy Management Tape, Nasco, Fort Atkinson, WI) around the chest, placed snugly behind the front legs and shoulder blades.

\section{Hoof Measurements}

Hoof measurements were taken from the right and left rear legs using a caliper (Carrera Precision 9806- 
TF, Max Tool LLC, La Verne, CA) and an angle gauge (Digital Protractor 11, iGaging, San Clemente, CA), and included the dorsal wall length, total claw length, heel height, and angle of both medial and lateral claws. In addition, the depth of the sole at $35 \mathrm{~mm}$ was obtained from the lateral claw of each rear foot (Figure 1) using a profile gauge (833 10" Contour Gage, General, New York, NY). The depth and hygiene of the interdigital space was also evaluated in each foot using the caliper, as well as the level of HHE. The HC traits were defined as follows: The dorsal wall length was defined as the distance from the beginning of the hard border of the hoof wall at the dorsal aspect of the coronary band to the tip of the claw [Figure 1 (D)]. The total claw length was defined as the distance between the tip of the claw and the proximal skin-horn junction at the caudo-lateral aspect of the heel [Figure $1(\mathrm{~T})]$. The heel height was defined as the perpendicular distance between the most distal point of the sole surface and the skin-horn junction of the heel [Figure $1(\mathrm{H})]$. The angle of the claw was defined as the angle described by the upwards inclination of the dorsal wall and the hoof sole [Figure $1(\mathrm{~A})$ ]. The depth of the sole was measured at $35 \mathrm{~mm}$ width distance from the abaxial side of the claw contour of the lateral claw [Figure 1 (P35)] as described in Telezhenko et al. (2009). When the sole depth passed below the horizontal reference line, values were considered negative and inversely, when the sole depth was observed above the reference line, values were considered positive. The interdigital cleft depth was defined as the distance between the skin-horn junction of the lateral and medial heels and the proximal end of the skin fold at the plantar aspect of the foot [Figure 1 (I)].
The shorter measure was recorded when the medial and lateral skin-horn borders were unleveled to measure the interdigital space fold. The hygiene of the interdigital space was classified using a 4-point scale depending on the level of debris accumulation $(1=$ clean interdigital skin; 2 = discontinuous accumulation of debris; $3=$ continuous accumulation of debris; and $4=$ complete filling of the interdigital space). Heel horn erosion was classified in 4 categories depending on the number and shape of the erosions (none $=$ smooth healthy horn covering the heel; diffuse $=$ focal erosive areas without a defined pattern; $\mathrm{V}$-shaped $=$ presence of $<2$ erosive fissures at the skin-horn border on the right and left heels; and layered $=$ presence of $2+$ fissures on both sides of the interdigital skin-horn border of the heel).

In addition, at enrollment, a $\sim 5 \mathrm{~mm}$ long and $\sim 1 \mathrm{~mm}$ depth mark was placed on the dorsal aspect of the left hoof wall by using a metal cutting wheel (Dremel EZ lock 1-1/2," Dremel, Mount Prospect, IL) to evaluate hoof wear and growth. The mark was initially placed about $2 \mathrm{~cm}$ down the hard border of the hoof wall [Figure $1(\mathrm{~m})]$. Hoof growth and wear monthly rates were calculated as the distance advanced by the mark toward the tip of the claw between evaluations [Figure $1(\mathrm{G})]$ and as the difference between the dorsal wall length and the distance from the mark and the tip of the claw [Figure $1(\mathrm{~W})$ ], respectively divided by the time in months between evaluations.

\section{Digital Dermatitis Classification}

Digital dermatitis lesions were characterized by their size ( $\mathrm{mm}$ measured across the greater dimension),
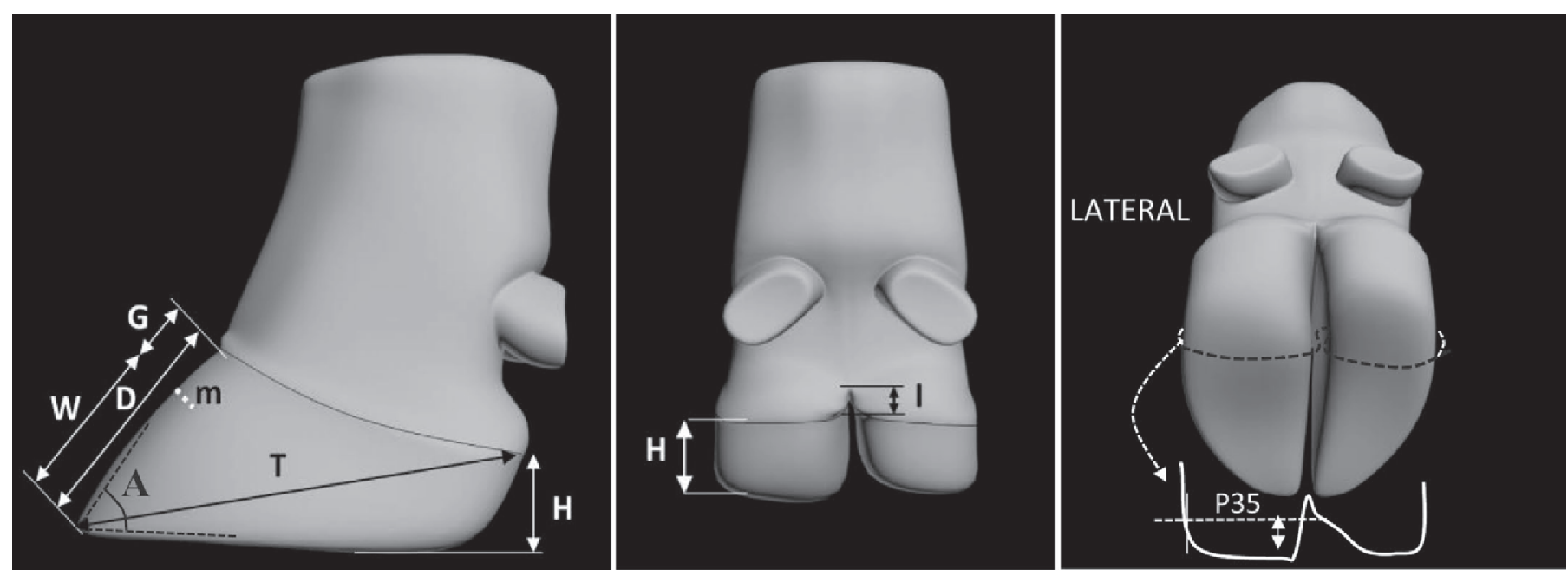

Figure 1. Description of the hoof measurements performed in both claws [dorsal wall length (D), growth $(\mathrm{G})$, wear $(\mathrm{W})$, height of the heel $(\mathrm{H})$, total hoof length $(\mathrm{T})$, and claw angle $(\mathrm{A})$ ], only on the lateral claw [overgrowth of the axial aspect of the lateral claw measured at $35 \mathrm{~mm}$ from the lateral hoof wall (P35)] or at the interdigital space [interdigital cleft depth (I)]. $\mathrm{m}=$ mark placed $\sim 2 \mathrm{~cm}$ from the coronary band used to evaluate hoof growth and wear. 
presence of proliferation (4-point scale in ascending severity: none, scale, mass-like, and filamentous), and location (heel, interdigital, dorsal, or other location). A 5-point scale according to Döpfer et al. (1997) and Berry et al. (2012) was used to classify the DD stages. Namely, lesions were classified as M0 if no lesions compatible with DD were observed on the foot; $\mathbf{M 1}$ and M4.1 if a DD lesion $<20 \mathrm{~mm}$ in its greater dimension was observed surrounded by healthy skin or embedded in a circumscribed dyskeratotic or proliferative skin alteration, respectively; M2 if an active lesion was found with a diameter $\geq 20$ skin $\mathrm{mm}$; M4 if only a circumscribed dyskeratotic or proliferative alteration was identified; and M3 if the lesions presented a dry brown and scab-like tissue within few days after topical treatment. Upon detection of an M2 DD lesion, topical treatment with $\sim 15 \mathrm{~mL}$ of dry tetracycline $\mathrm{HCl}$ powder (Tet-sol 324, Alpharma Inc., Fort Lee, NJ) was applied under a light wrap that was removed within less than 48 h. Other DD stages were left untreated. Heifers with concurrent horn and skin lesions $(<1 \%, \mathrm{n}=3)$ were removed from the data set before the evaluation of $\mathrm{DD}$ effects on HC. No hoofbaths were used during the study period.

\section{Statistical Analysis}

Statistical analysis was performed at foot level to evaluate differences in $\mathrm{HC}$ characteristics observed overtime between healthy and M2 affected feet. Mixed linear multiple variable regression was selected to perform the analysis. The goal was to quantify the mean effect of DD on $\mathrm{HC}$ after accounting for the changes that could have happened over time in the absence of DD. In the model, the estimated effect attributable to the disease is specified by an interaction term between the disease and the follow-up time to adjust for differences in follow-up time between animals and changes in $\mathrm{HC}$ due to reasons other than the disease. For the analysis, the interdigital hygiene and HHE variables were dichotomized for ease of interpretation as interdigital hygiene scores $<3$ vs. 3 to 4 , and heel horn erosion as "layered" (greatest severity) vs. other than "layered."

The model equation [1] is shown below:

$$
\begin{aligned}
Y=\beta_{0} & +\beta_{1} \mathrm{TFU}_{\mathrm{i}}+\beta_{2} \mathrm{DD} \mathrm{stage}_{i}+\beta_{3} \mathrm{TFU}_{i} \\
& \times \mathrm{DD} \mathrm{stage}_{i}+\alpha \mathrm{X}_{j}+\nu_{j}+\mathrm{e}_{i j},
\end{aligned}
$$

where $Y=$ each of the hoof characteristics; $\mathrm{TFU}_{i}=$ continuous variable indicating the follow-up time between evaluations; DD stage $_{i}=$ DD stage at each of the evaluations (M0 or M2); $\beta_{3}=$ estimate of the interaction term between TFU and DD stage; $\alpha \mathrm{X}_{j}=$ a vector of demographic covariates at the beginning of the observation period (age, heart-girth $\times$ hip-height, DCC); and $\nu_{j}=$ random term for heifer.

Hoof wear and hoof growth rates per month were calculated using information from 2 different evaluations and a mixed multivariable model [2] was used to evaluate rate differences between healthy and M2 affected heifers as follows:

$$
Y=\beta_{0}+\beta_{1} \text { period }_{\mathrm{i}}+\beta_{2} \mathrm{DD}_{\text {stage }_{\mathrm{i}}}+\alpha \mathrm{X}_{j}+\nu_{j}+e_{i j}
$$

where $Y=$ hoof wear or hoof growth rate, $\operatorname{period}_{i}=$ time of hoof growth and hoof wear calculation $(1=$ between evaluation 1 and 2 , or $2=$ between evaluations 2 and 3), DD stage $_{i}=$ DD stage observed during periods 1 or $2, \alpha \mathrm{X}_{j}=$ a vector of demographic characteristics covariates (age, heart-girth $\times$ hip-hip-height, DCC), and $\nu_{j}=$ random term for heifer.

To account for repeated measurements within the same heifers a random term for heifer ID was included in the models. Residual plots were used to assess goodness of fit, linear trends, and heteroskedasticity. Significance was set at the $95 \%$ confidence level. All final models were selected by the backward elimination method from the basic model and forward selection method when additional simple or double interactions were tested. The likelihood ratio test to discriminate between nested models and the Akaike's information criterion between nonnested models was used to select the best parsimonious model.

Hoof conformation records of 238 heifers that were randomly selected to receive a functional hoof trimming between evaluation 2 and evaluation 3 as part of a different study were removed from the analysis because of conformation changes due to hoof trimming. The statistical R software version 3.0.3 was used to perform the analysis of the data (R Core Team, 2014).

\section{Effects of Persistent DD on HC}

To quantify the short-term effect of DD on the persistency on $\mathrm{HC}$ changes after M2 DD lesions were topically treated, an analysis similar to that described under Eq. [1] was performed in a sub-cohort of 26 heifers (29 feet records). The comparison in $\mathrm{HC}$ was made between heifers identified with an M2 lesion at evaluation 2 and heifers either presenting no signs of DD (M0) or recorded with an M2 lesion at evaluation 3. Recovery from an M2 to an M0 stage was determined when the previously M2 affected area was observed in the subsequent evaluation without any signs of disease, presenting normal color skin, and no hyperkeratosis. For this 
Table 2. Hoof conformation characteristics [mean, (SD)] observed at each evaluation

\begin{tabular}{|c|c|c|c|c|c|c|}
\hline Hoof characteristic & \multicolumn{2}{|c|}{ Evaluation 1} & \multicolumn{2}{|c|}{ Evaluation 2} & \multicolumn{2}{|c|}{ Evaluation 3} \\
\hline Total length (mm) & $128.5(6.5)$ & $129.1(7.5)$ & $129.1(5.6)$ & $128.8(6.5)$ & $130.9(5.7)$ & $130.6(6.2)$ \\
\hline Claw angle (degrees) & $47.2(3.1)$ & $48.9(3.5)$ & $47.9(3.5)$ & $50.9(3.5)$ & $47.1(3.4)$ & $50.1(3.7)$ \\
\hline Heel height $(\mathrm{mm})$ & $32.6(5.3)$ & $33.6(4.5)$ & $31.2(4.9)$ & $33.4(4.2)$ & $32.3(4.9)$ & $34.4(4.1)$ \\
\hline Depth interdigital cleft $(\mathrm{mm})$ & \multicolumn{2}{|c|}{$13.5(2.5)$} & \multicolumn{2}{|c|}{$14.4(2.9)$} & \multicolumn{2}{|c|}{$14.8(3.0)$} \\
\hline Heel horn erosion (\% layered) $[\%$ (no./total)] & $\begin{array}{r}11.5(150 / 1,288) \\
1.9(25 / 1,288)\end{array}$ & $25 / 1,288)$ & $17.1(217 / 1,267)$ & $121 / 1,267)$ & 24.4 & $(174 / 712)$ \\
\hline
\end{tabular}

analysis, only $\mathrm{HC}$ traits showing statistical significance during the analysis under Eq. [1] were considered for evaluation.

\section{RESULTS}

The M2 lesions were associated with severe $\mathrm{HC}$ changes in affected feet. Although overall $\mathrm{HC}$ did not vary significantly during the study period when all animals were considered, (Table 2), the presence of an M2 lesion [mean $(\mathrm{SD})$ size $=27.2(8.2) \mathrm{mm}$ ] caused the $\mathrm{HC}$ to be significantly changed in relation to animals never experiencing an M2 event. The M2 lesions were found mainly affecting the heel area [95\% (149/157)], and were associated with skin proliferation and skin dyskeratosis in $20 \%(32 / 157)$ and $99 \%(155 / 157)$ of the cases, respectively. The M2 DD lesions recorded during evaluation 2 and 3 (Table 3 ) were similar, and no lameness was observed in any of the DD affected heifers. The cohort of heifers was very homogeneous (Table 1), and the size of the cohort did not change significantly during the study ( $<1 \%$ losses to follow-up).

The analysis demonstrated statistically significant differences between healthy and M2 affected heifers in medial and lateral claw angles, medial and lateral heel heights, depth of the interdigital space, level of interdigital hygiene, and incidence of HHE (Table 4). Similar DD effects could be observed when other DD stages were analyzed. As an example, a diagram of the differences in depth of the interdigital space and incidence of heel horn erosion is shown in Figure 2 for heifers never experiencing DD and animals transitioning to any DD stage.

Nonsignificant differences in hoof growth and hoof wear rates over time were observed between healthy and M2 affected heifers (Table 5). It is remarkable that the overall balance observed was negative when comparing the mean (SD) hoof growth and hoof wear on lateral [6.4 (1.9) vs. $6.9(2.7) \mathrm{mm}$, respectively] and medial claws [6.0 (1.8) vs. $6.6(2.9) \mathrm{mm}$ respectively], independent of the DD infection status.

\section{Effects of Persistent DD on HC}

Evaluation of the short-term $\mathrm{HC}$ changes after treatment was conducted in a subgroup of animals diagnosed with an M2 event during evaluation 2 (Table 6 ). Hoof conformation traits that were significantly modified upon M2 diagnosis at evaluation 2, such as heel height and claw angle of the lateral and medial claws, depth of the interdigital cleft, and HHE, tended to decrease when the initial M2 lesions were resolved after treatment (M0 diagnosis at evaluation 3). Alternatively, increased values in $\mathrm{HC}$ characteristics were observed in feet diagnosed with repeat cases of M2 DD at evaluation 3 .

\section{DISCUSSION}

We have demonstrated how M2 lesions modify HC before lameness caused by DD becomes apparent. In the field, it is common practice that only severe cases of DD receive medical attention. Therefore, DD affected animals are generally recruited for individual treatment during regular claw trimming and when they show symptoms of lameness. In these cases, it is not unlikely that $\mathrm{HC}$ has changed, resulting in significantly overgrown heels, shortened claws, and severe heel horn erosion. In addition, when recruitment of DD cases is delayed, lesions are left untreated and repeated DD events may have affected the same foot, resulting in skin proliferation at the lesion site such as hyperkeratotic, filamentous, or elevated mass-like skin dyskeratosis. For example, in a cross-sectional study by Read and Walker (1998), the presence of skin proliferation was found in $>30 \%$ of 82 cow cases recruited from 9 California dairies. The results of our study clearly show that $\mathrm{HC}$ changes happen as early as the onset of clinical events. Prompt intervention upon diagnosis of DD lesions would be recommended to avoid further pathological $\mathrm{HC}$ and skin changes.

This longitudinal study allowed us to evaluate $\mathrm{HC}$ differences observed over time between healthy animals 
Table 3. Characteristics of M2 lesions observed at each of the evaluations

\begin{tabular}{|c|c|c|c|c|}
\hline \multirow{3}{*}{$\begin{array}{l}\text { Lesion characteristic } \\
\text { No. of total events (feet) recorded } \\
\text { DD }^{1} \text { stage }(\%, \text { no. })\end{array}$} & \multicolumn{2}{|c|}{ Evaluation 2} & \multicolumn{2}{|c|}{ Evaluation 3} \\
\hline & \multirow{2}{*}{\multicolumn{2}{|c|}{1,266}} & \multirow{2}{*}{\multicolumn{2}{|c|}{712}} \\
\hline & & & & \\
\hline M0 & 79.5 & 1,007 & 69.9 & 498 \\
\hline M1 & 6.3 & 81 & 5.3 & 38 \\
\hline M2 & 5.5 & 70 & 12.2 & 87 \\
\hline M4 & 5.2 & 67 & 6.9 & 49 \\
\hline M4.1 & 3.2 & 41 & 5.6 & 40 \\
\hline N M2 DD events & 70 & & & 87 \\
\hline $\operatorname{Size}^{2}(\mathrm{~mm})[$ mean $(\mathrm{SD})]$ & 26.3 & 8.0 & 27.8 & 8.3 \\
\hline \multicolumn{5}{|l|}{ Location $^{3}$ (\%, no.) } \\
\hline Heel & 94.0 & 66 & 83 & 96 \\
\hline Lateral & 1.4 & 1 & 2 & 2.3 \\
\hline Dorsal & 1.4 & 1 & 0 & 0 \\
\hline Interdigital & 3.2 & 2 & 2 & 2.3 \\
\hline \multicolumn{5}{|l|}{ Proliferation $^{4}(\%$, no. $)$} \\
\hline None & 80 & 56 & 80 & 69 \\
\hline Filamentous & 14 & 10 & 10 & 9 \\
\hline Other & 6 & 4 & 10 & 9 \\
\hline \multicolumn{5}{|l|}{$\operatorname{Signs}^{5}(\%$, no. $)$} \\
\hline None & 1.4 & 1 & 1.1 & 1 \\
\hline Dyskeratosis & 91 & 64 & 94 & 82 \\
\hline $\mathrm{OLH}$ & 7.6 & 5 & 4.6 & 4 \\
\hline
\end{tabular}

${ }^{1} \mathrm{DD}=$ digital dermatitis.

${ }^{2}$ Size $=$ diameter across the greatest dimension.

${ }^{3}$ Location: heel $=$ plantar aspect of the hoof between the heel bulbs including the interdigital cleft at the heel, dorsal $=$ dorsal aspect of the hoof centered between the claws; lateral = medial or lateral coronary band; interdigital $=$ interdigital space, out of the heel area.

${ }^{4}$ Proliferation: filamentous $=$ presence of filamentous skin proliferation of any size; other $=$ presence of any type of skin proliferation (either shown as a scale or a mass-like protrusion of the lesion).

${ }^{5}$ Signs: dyskeratosis $=$ presence of a well-delimited rough and dyskeratotic skin area; OLH = presence of overlong hair.

and animals experiencing a DD event after adjusting for individual follow-up time differences, baseline characteristics and $\mathrm{HC}$ changes due to reasons other than DD (Table 5). Presence of M2 lesions were found to be significantly associated with an increase in claw angle, heel height, depth of the interdigital cleft, the accumulation of debris in the interdigital space, and also with increased incidence and severity of HHE.

In contrast to our study where DD significantly increased the heel height of both claws, a previous study by Laven (2007) showed a negative association between heel height and DD occurrence. However, the author attributed this association to the increased probability of DD infection in low claw heels due to their proximity to the ground, rather than to the causal effect of DD on HC. We agree with Laven (2007) that, to reduce discomfort associated with DD, cattle tend to stand on their claws, taking weight off their heels. This change in stance results in increased claw heel height. As a consequence of the increase in claw heel height and given that the claw length remained unchanged, a significant increase in claw angle was observed in feet affected by M2 DD.

Part of the HC changes in the claw heel area is a deeper interdigital cleft. The association between the depth of the interdigital space and DD occurrence had been previously reported by Daniel (2011). However, the cross-sectional nature of Daniel's study did not establish a temporal relationship between deep interdigital spaces and DD infection. Our results showed that significant changes of the interdigital space depth occurred in animals experiencing an M2 lesion and that was not observed in healthy animals [mean $(95 \%$ CI) $3.2(2.69,3.71) \mathrm{mm}$. Inflammation of skin tissue (Gomez et al., 2012) and the prominence of the DD lesion in relation to the surrounding healthy skin (Read and Walker, 1998) can explain the observed increase in depth of the interdigital space. As reported in a previous study by Walker et al. (2002), significantly larger accumulation of debris was also found in the interdigital space of feet affected by DD.

In agreement with Daniel (2011), once the disease is established, deeper interdigital spaces can favor anaerobic environments and potentially facilitate the development of DD stages, resulting in increased bacterial growth and disease recurrence.

Increased cases of severe HHE complete the transformation of DD affected claw heels. Notably, an adjusted 46 (95\% CI, 40 to 49) percent points increase of the layered HHE category (49 vs. 1\%) was described in feet 
Table 4. Adjusted mean (95\% CI) hoof conformation measurements and mean differences observed between heifers experiencing M2 lesions and healthy heifers ${ }^{1}$

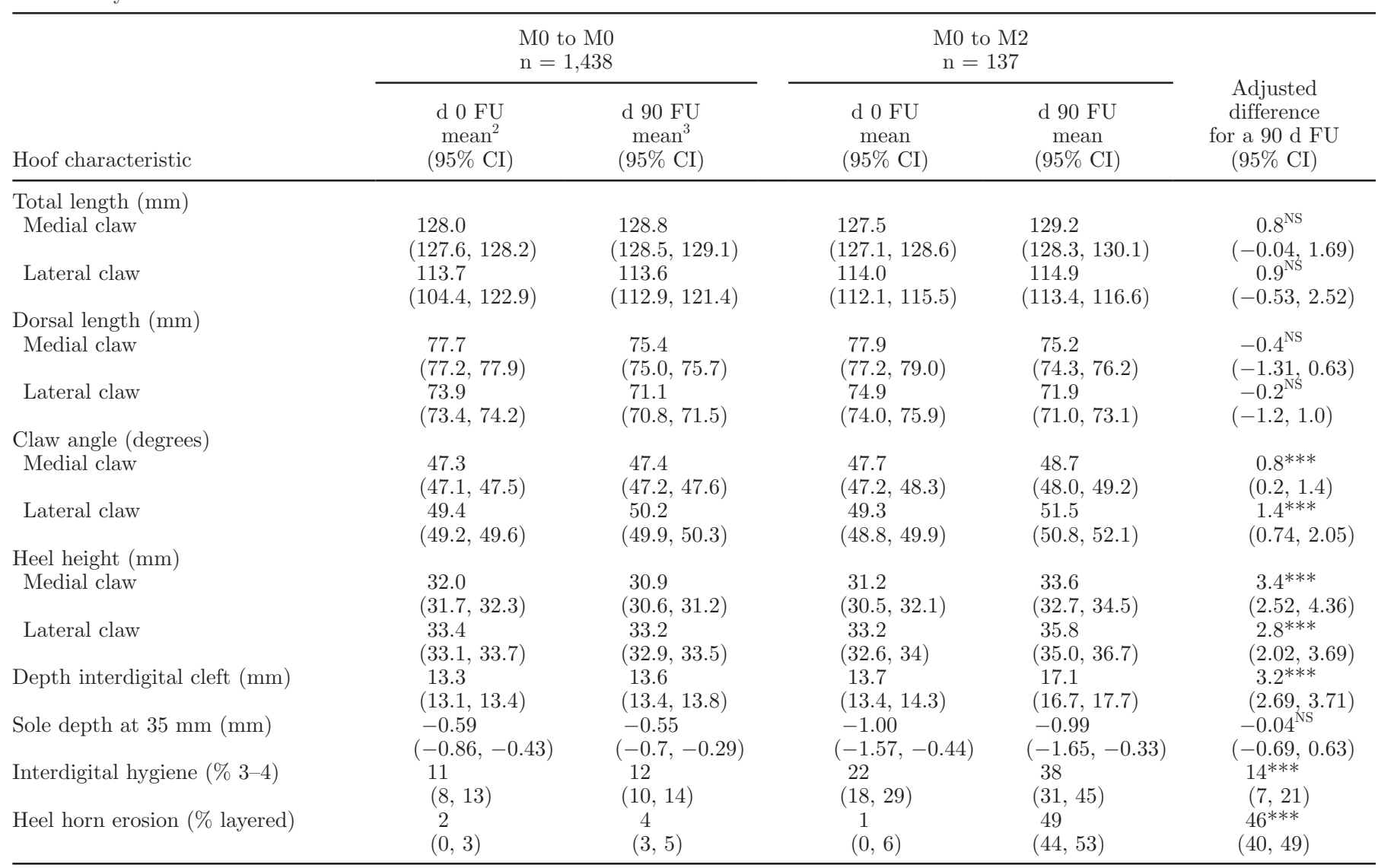

${ }^{1}$ Estimates are shown for a 90-d follow-up period, and adjusted for age, days pregnant, girth circumference, and height.

${ }^{2} \mathrm{~d} 0 \mathrm{FU}=$ first day of the follow-up period.

${ }^{3} \mathrm{~d} 90 \mathrm{FU}=90 \mathrm{~d}$ follow-up period.

$* * * P<0.01$

affected with DD in comparison with feet not affected by DD. The association between heel horn erosion, interdigital dermatitis, and DD had been largely reported in the literature (Manske et al., 2002; Somers et al., 2005; Holzhauer et al., 2008). This association had been attributed to the fact that DD, interdigital dermatitis, and HHE share common risk factors such as wet and muddy environments (Walker et al., 2002; Somers et al., 2005) and some bacterial species have been found in all 3 diseases as is the case for D. nodosus or Treponema spp. (Rasmussen et al., 2012; Knappe-Poindecker et al., 2013). For the first time, a temporal association has been shown between DD and layered HHE by the current study. It is our belief that the occurrence of a clinical DD event initiates the ideal conditions for the development of more severe HHE. Less severe cases of DD (M1, M4, or M4.1) also demonstrated a tendency to modify HC (depth of the interdigital cleft and HHE are shown in Figure 2) in our study.
The relationship of DD with hoof growth and wear, and depth of the sole of the lateral claw were also evaluated. It was hypothesized that the presence of DD would lead to differences in hoof wear and hoof growth because of locomotion changes meant to avoid pain and discomfort in the DD-affected area. As shown in Table 4, no significant differences in hoof wear and hoof growth were observed in our data set. This could be explained by the fact that early M2 cases do not influence hoof wear and growth, and perhaps only severe DD cases result in changes of hoof wear and growth. Second, it is known that different types of flooring influence hoof wear and growth (Telezhenko et al., 2009) and are associated with DD occurrence (Frankena et al., 2009). Our research was conducted in a facility with recycled-sand bedding material. The effect of sand in concrete alleys on hooves causing aggressive wear may have masked the effects of DD on hoof wear and growth and depth of the sole. Similarly, results observed with regards to 
Table 5. Hoof wear and hoof growth rates per month observed in healthy and M2 affected heifers

\begin{tabular}{|c|c|c|c|c|c|c|}
\hline \multirow{4}{*}{$\begin{array}{l}\text { Item } \\
\text { No. of observations } \\
\text { Hoof growth rate (mean, SD) mm/mo }\end{array}$} & \multicolumn{2}{|c|}{ M0 to M0 } & \multicolumn{2}{|c|}{ M0 to M2 } & \multicolumn{2}{|c|}{$\begin{array}{l}\text { Adjusted mean difference } \\
\text { estimates (95\% CI) } \\
\text { [M0 to M0 (Ref.)] }\end{array}$} \\
\hline & \multicolumn{2}{|c|}{504} & \multicolumn{2}{|c|}{42} & & \\
\hline & & & & & & \\
\hline & 6.4 & $(1.9)$ & 5.9 & $(2.0)$ & $-0.47^{\mathrm{NS}}$ & $(-1.12,0.04)$ \\
\hline Medial claw & 6.0 & $(1.8)$ & 5.7 & (1.1) & $-0.24^{\mathrm{NS}}$ & $(-0.81,0.26)$ \\
\hline \multicolumn{7}{|l|}{ Hoof wear rate (mean, $\mathrm{SD}$ ) $\mathrm{mm} / \mathrm{mo}$} \\
\hline Lateral claw & 6.9 & $(2.7)$ & 6.4 & $(2.6)$ & $-0.40^{\mathrm{NS}}$ & $(-1.12,0.28)$ \\
\hline Medial claw & 6.6 & $(2.9)$ & 6.2 & $(2.1)$ & $-0.73^{\mathrm{NS}}$ & $(-0.88,0.67)$ \\
\hline
\end{tabular}

the depth of the sole of the lateral claw might have been masked by the type of study facilities. Facilities using other types of bedding materials would need to be included in future research to further explore the relationship between hoof wear, DD, and barn flooring.

A data subset was used to evaluate the persistence of $\mathrm{HC}$ changes when M2 affected feet transitioned back to the healthy stage (M0). Although no significant differences for all $\mathrm{HC}$ traits were observed in the small sample size of the sub-cohort, the direction of events observed was as expected. Heel height and claw angle of the medial and lateral claws and depth of the in-
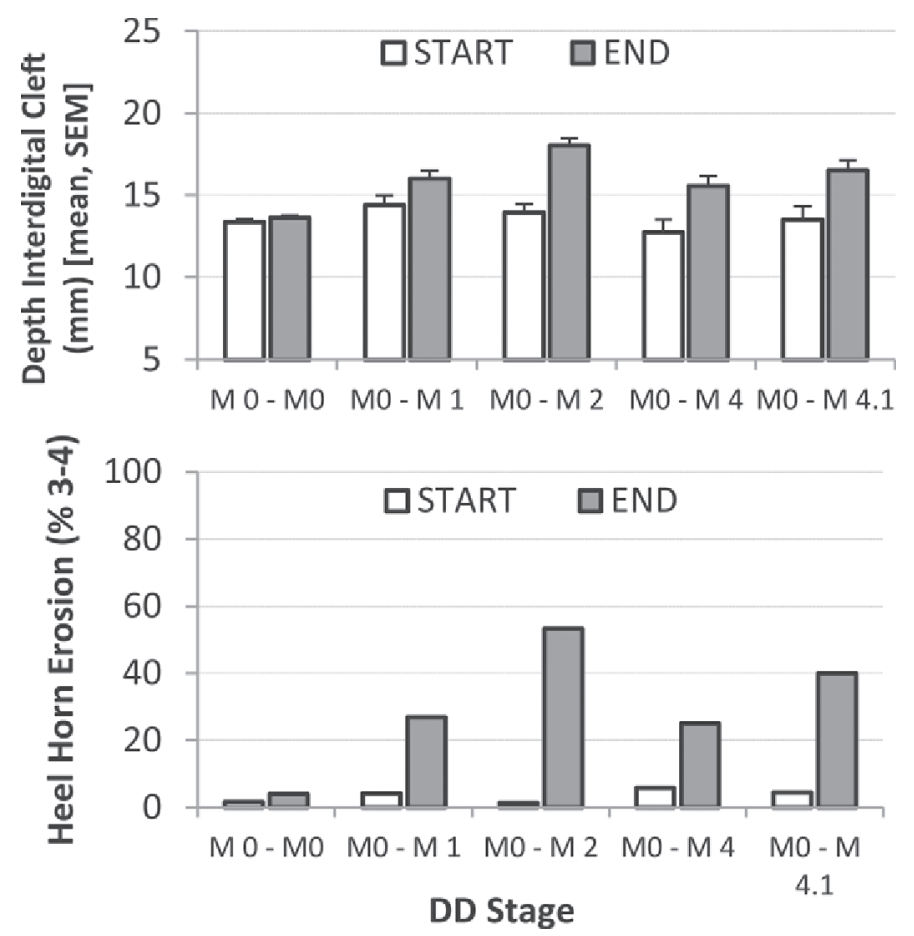

Figure 2. Differences observed over time in depth of the interdigital space and incidence of layered heel horn erosion between feet never diagnosed with digital dermatitis (DD; M0 to M0) and feet diagnosed with an M2 DD stage (M0 to M2) or any other DD stage (M0 to M1, M0 to M4, and M0 to M4.1) during a follow-up period of $90 \mathrm{~d}$. Differences adjusted for age, days pregnant, girth circumference, and height. terdigital cleft decreased and the percentage of feet showing severe HHE remained constant after DD was resolved (Table 6). These results make the previously demonstrated causal relationship between DD and $\mathrm{HC}$ more plausible and if DD is cured the $\mathrm{HC}$ reverts back to normal. In addition, the findings are motivating to act more promptly upon detection of clinical M2 cases.

In addition to the inclusion of time in the analysis, an additional strength of the study is the use of heifers as study participants. First, because DD has been reported to be the most prevalent foot disease in young stock (NAHMS Dairy, 2007) where DD has great implications for subsequent DD control in adult cows (Laven and Logue, 2007). Digital dermatitis control programs should therefore be focused on controlling the disease in heifers. Second, HC changes observed in the study are less likely to be confounded by other hoof diseases commonly found in adult cattle (DeFrain et al., 2013).

\section{CONCLUSIONS}

Significant HC changes occurred in heifers affected by M2 DD before lameness symptoms were detected. The transformation of the heel area in feet affected by DD likely promotes a micro-environment that increases the persistence of the disease and favors the occurrence of severe HHE. To avoid further hoof damage, active surveillance and early intervention are the recommended approaches to improve DD control programs. Therefore, based on the DD incidence of each particular farm, weekly to monthly assessment of the DD status should be performed in all animals with subsequent topical treatment of the M2 cases diagnosed. In the short-term, successful restoration of $\mathrm{HC}$ characteristics can be achieved upon clinical cure of DD. Long-term effects of DD control in relation to other hoof diseases and lifetime performance must be further investigated.

\section{ACKNOWLEDGMENTS}

This study was supported by Zinpro Corporation (Eden Prairie, MN). 
Table 6. Adjusted mean (95\% CI) hoof conformation characteristics and mean differences observed in M2 digital dermatitis heifers after treatment $^{1}$

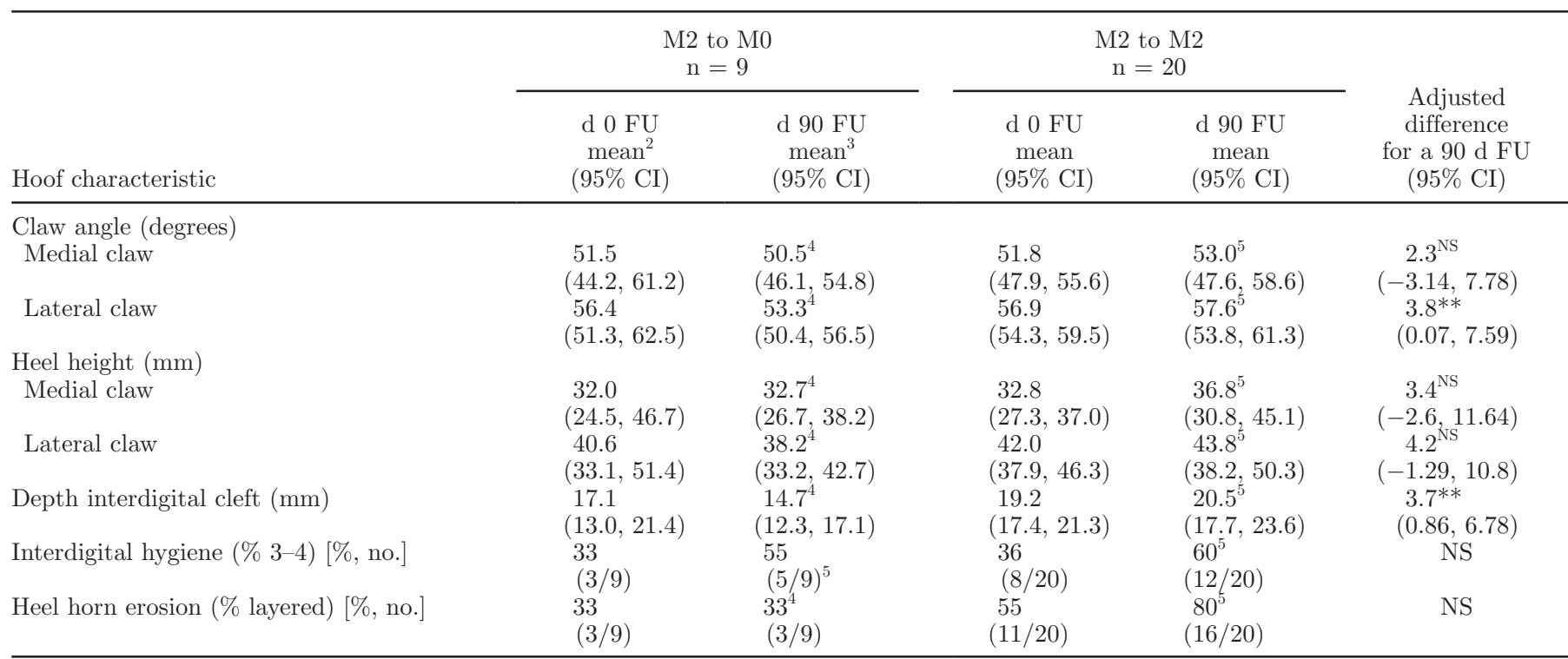

${ }^{1}$ Estimates shown have been standardized to a 90-d follow-up, and adjusted for age, days pregnant, girth circumference, and height.

${ }^{2} \mathrm{~d} 0 \mathrm{FU}=$ first day of the follow-up period.

${ }^{3} \mathrm{~d} 90 \mathrm{FU}=90 \mathrm{~d}$ follow-up period.

${ }^{4}$ Decreased or maintained hoof conformation characteristic between evaluation 2 and 3.

${ }^{5}$ Increased hoof conformation characteristic between evaluation 2 and 3.

$* * P<0.05$.

\section{REFERENCES}

Baird, L. G., N. E. O'Connell, M. A. McCoy, T. W. J. Keady, and D. J. Kilpatrick. 2009. Effects of breed and production system on lameness parameters in dairy cattle. J. Dairy Sci. 92:2174-2182.

Becvar, O., W. S. Swecker, D. L. Ward, G. Scaglia, J. P. S. Neel, and J. P. Fontenot. 2005. Effect of housing system and nutrition on claw horn growth and abrasion in beef steers. Page 211 in Proc. Am. Assoc. Bov. Pract. Salt Lake City, UT. V M Publishing, Stillwater, OK.

Berry, S. L., D. H. Read, T. R. Famula, A. Mongini, and D. Döpfer 2012. Long-term observations on the dynamics of bovine digital dermatitis lesions on a California dairy after topical treatment with lincomycin $\mathrm{HCl}$. Vet. J. 193:654-658.

Bicalho, R. C., V. S. Machado, and L. S. Caixeta. 2009. Lameness in dairy cattle: A debilitating disease or a disease of debilitated cattle? A cross-sectional study of lameness prevalence and thickness of the digital cushion. J. Dairy Sci. 92:3175-3184.

Capion, N., S. M. Thamsborg, and C. Enevoldsen. 2008. Prevalence of foot lesions in Danish Holstein cows. Vet. Rec. 163:80-85.

Chapinal, N., A. Koeck, A. Sewalem, D. F. Kelton, S. Mason, G. Cramer, and F. Miglior. 2013. Genetic parameters for hoof lesions and their relationship with feet and leg traits in Canadian Holstein cows. J. Dairy Sci. 96:2596-2604.

Daniel, V. 2011. Digital dermatitis and inter-digital dermatitis infection risks increase as inter-digital cleft space in Holsteins decrease. Page 14 in Proc. Int. Symp. Lameness Rumin. Rotorua, New Zealand. Accessed Sep. 1, 2014. www.lamenessinruminants.org/docs/ LIR2011 Handbook.pdf.

DeFrain, J. M., M. T. Socha, and D. J. Tomlinson. 2013. Analysis of foot health records from 17 confinement dairies. J. Dairy Sci. 96:7329-7339

Döpfer, D., A. Koopmans, F. A. Meijer, I. Szakall, Y. H. Schukken, W. Klee, R. B. Bosma, J. L. Cornelisse, A. vanAsten, and A. terHuurne. 1997. Histological and bacteriological evaluation of digi- tal dermatitis in cattle, with special reference to spirochaetes and Campylobacter faecalis. Vet. Rec. 140:620-623.

Fjeldaas, T., A. M. Sogstad, and O. Osterås. 2011. Locomotion and claw disorders in Norwegian dairy cows housed in freestalls with slatted concrete, solid concrete, or solid rubber flooring in the alleys. J. Dairy Sci. 94:1243-1255.

Flower, F. C., and D. M. Weary. 2009. Gait assessment in dairy cattle. Animal 3:87-95.

Frankena, K., J. G. C. J. Somers, W. G. P. Schouten, J. V. van Stek, J. H. M. Metz, E. N. Stassen, and E. M. Graat. 2009. The effect of digital lesions and floor type on locomotion score in Dutch dairy cows. Prev. Vet. Med. 88:150-157.

Gomez, A., and N. B. Cook. 2010. Time budgets of lactating dairy cattle in commercial freestall herds. J. Dairy Sci. 93:5772-5781.

Gomez, A., N. B. Cook, N. D. Bernardoni, J. Rieman, A. F. Dusick, R. Hartshorn, M. T. Socha, D. H. Read, and D. Doepfer. 2012. An experimental infection model to induce digital dermatitis infection in cattle. J. Dairy Sci. 95:1821-1830.

Greenough, P. R. 2007. Bovine Laminitis and Lameness: A Hands On Approach. 1st ed. Saunders, Elsevier Ltd., Philadelphia, PA.

Häggman, J., and J. Juga. 2013. Genetic parameters for hoof disorders and feet and leg conformation traits in Finnish Holstein cows. J. Dairy Sci. 96:3319-3325.

Holzhauer, M., C. J. M. Bartels, D. Dopfer, and G. van Schaik. 2008. Clinical course of digital dermatitis lesions in an endemically infected herd without preventive herd strategies. Vet. J. 177:222230.

Holzhauer, M., B. Brummelman, K. Frankena, and T. J. G. M. Lam. 2012. A longitudinal study into the effect of grazing on claw disorders in female calves and young dairy cows. Vet. J. 193:633-638.

Knappe-Poindecker, M., M. Gilhuus, T. K. Jensen, K. Klitgaard, R. B. Larssen, and T. Fjeldaas. 2013. Interdigital dermatitis, heel horn erosion, and digital dermatitis in 14 Norwegian dairy herds. J. Dairy Sci. 96:7617-7629.

Laven, R. A. 2007. The relationship between hoof conformation and digital dermatitis in dairy cattle. Cattle Pract. 15:93-95. 
Laven, R. A., and D. N. Logue. 2007. The effect of pre-calving environment on the development of digital dermatitis in first lactation heifers. Vet. J. 174:310-315.

Manske, T., J. Hultgren, and C. Bergsten. 2002. Topical treatment of digital dermatitis associated with severe heel-horn erosion in a Swedish dairy herd. Prev. Vet. Med. 53:215-231.

NAHMS Dairy. 2007. Part V: Changes in Dairy Cattle Health and Management Practices in the United States, 1996-2007. USDAAPHIS-VS-CEAH, Fort Collins, CO, Accessed January 2014. http://www.aphis.usda.gov/animal_health/nahms/dairy/downloads/dairy07/Dairy07_dr_PartV_rev.pdf.

Navarro, G., L. E. Green, and N. Tadich. 2013. Effect of lameness and lesion specific causes of lameness on time budgets of dairy cows at pasture and when housed. Vet. J. 197:788-793.

Offer, J. E., D. McNulty, and D. N. Logue. 2000. Observations of lameness, hoof conformation and development of lesions in dairy cattle over four lactations. Vet. Rec. 147:105-109.

Olechnowicz, J., and J. M. Jaskowski. 2010. Hoof measurements related to locomotion scores and claw disorders in dairy primiparous cows. Bull. Vet. Inst. Pulawy 54:87-92.

Ouweltjes, W., M. Holzhauer, P. P. J. van der Tol, and J. van der Werf. 2009. Effects of two trimming methods of dairy cattle on concrete or rubber-covered slatted floors. J. Dairy Sci. 92:960-971.

R Core Team. 2014. R: A language and environment for statistical computing. R Foundation for Statistical Computing. Vienna, Austria.
Rasmussen, M., N. Capion, K. Klitgaard, T. Rogdo, T. Fjeldaas, M. Boye, and T. K. Jensen. 2012. Bovine digital dermatitis: Possible pathogenic consortium consisting of Dichelobacter nodosus and multiple Treponema species. Vet. Microbiol. 160:151-161.

Read, D., and R. Walker. 1998. Papillomatous digital dermatitis (footwarts) in California dairy cattle: Clinical and gross pathologic findings. J. Vet. Diagn. Invest. 10:67-76.

Somers, J. G. C. J., K. Frankena, E. N. Noordhuizen-Stassen, and J H. M. Metz. 2005. Risk factors for interdigital dermatitis and heel erosion in dairy cows kept in cubicle houses in The Netherlands. Prev. Vet. Med. 71:23-34.

Telezhenko, E., C. Bergsten, M. Magnusson, and C. Nilsson. 2009. Effect of different flooring systems on claw conformation of dairy cows. J. Dairy Sci. 92:2625-2633.

van der Linde, C., G. de Jong, E. P. C. Koenen, and H. Eding. 2010. Claw health index for Dutch dairy cattle based on claw trimming and conformation data. J. Dairy Sci. 93:4883-4891.

Walker, R. L., S. L. Berry, A. Rodriguez-Lainz, and D. Read. 2002. Prospective study on foot conformation characteristics predisposing to the development of papillomatous digital dermatitis. Page 370 in Proc. Int. Symp. Lameness Rumin., Orlando, FL. J. K. Shearer, Orlando, FL.

Winkler, B., and J. K. Margerison. 2005. Hoof measurements and their relationship to lameness in first lactation heifers. Page 208 in Proc. Br. Soc. Anim. Sci., Penicuik, UK. 